\title{
The impact of extreme wave events on a fixed multicolumn offshore platform
}

\author{
Nagi Abdussamie ${ }^{1}$, Roberto Ojeda ${ }^{1}$, Yuriy Drobyshevski ${ }^{l}$, Giles Thomas ${ }^{2}$, Walid Amin ${ }^{1}$ \\ ${ }^{I}$ Australian Maritime College Search (AMCS), University of Tasmania \\ Launceston, Tasmania, Australia \\ ${ }^{2}$ Department of Mechanical Engineering, University College London (UCL) \\ London, UK
}

\begin{abstract}
This paper presents an experimental and numerical investigation into the magnitude and distribution of the hydrodynamic loads affecting a fixed, multicolumn offshore platform (rigidly mounted TLP) when subjected to extreme wave events. All wave load components, including wave-in-deck slamming pressures, were predicted using a commercial CFD code STAR-CCM+ and compared against experimental measurements. Slamming pressures were calculated using both data obtained locally at discrete points and globally averaged over the whole exposed area of the deck. In all simulated cases, the deck area exposed to a wave slamming event was found to be in contact with a water-air mixture with a significant proportion of air phase. It was concluded that the slamming pressure data for the exposed area provided better insights into the pressure changes due to air compressibility and its content.
\end{abstract}

KEYWORDS: Offshore platforms; Wave-in-deck loads; slamming pressure.

\section{INTRODUCTION}

When a large wave (extreme wave event) impacts the deck of an offshore structure, significant wave-in-deck and slamming loads occur. These slamming events could generate major global and local loads which can cause structural damage to the deck, generating large forces in the tendons and risers and adversely affect the motions of floating structure such as Tension Leg Platforms (TLPs) and Semisubmersibles. The problem of wave-in-deck impact on a floating platform can be quite complicated because of the contributions of many parameters such as the platform offset, set-down and tendon dynamics (API, 2010).

The simplest way to investigate wave-in-deck impact problems is a simplified rigid model of the deck structure idealised as a flat plate or as a box-shape (Baarholm, 2009, Bhat, 1994, Scharnke and Hennig,
2015). Current design practices (API, 2007, DNV, 2010, ISO, 2007) recommend a number of theoretical approaches such as the global/silhouette approach "simplified loading model" (API, 2007) and a detailed component approach, e.g., the momentum method (Kaplan et al., 1995) to evaluate the wave-in-deck loads of fixed platforms. Since such engineering approaches rely on the potential flow theory to calculate the change of fluid momentum during the wave impact, using wave kinematics of a non-disturbed wave field, the effects of diffraction and entrapped air are neglected. Scharnke et al. (2014) found that the recommended simplified loading model (API, 2007, DNV, 2010) underestimates the measured horizontal wave-in-deck loads on a fixed deck of jacket platform in both regular and irregular wave tests. Even though the simplified loading model used wave kinematics obtained by Stokes fifth order wave theory, the underestimation of the loads was severe, particularly in irregular waves (Scharnke et al., 2014). The momentum method was also found to underestimate the magnitude of the wave-in-deck forces on a fixed horizontal deck subjected to unidirectional regular waves (Abdussamie et al., 2014b). A more realistic investigation into the wave-in-deck problems shall include the effect of substructures on the magnitude and distributions of the deck loads. Scharnke and Hennig (2015) conducted an experimental study by attaching a fixed box-type deck structure to a square column. The authors concluded that the column presence significantly increases the magnitude of global vertical forces and local pressures.

The current engineering knowledge, required to accurately predict the resulting global response of a floating structure due to a wave-in-deck impact event, remains limited. This fact is reflected in the very limited number of papers reporting on model tests of typical multi-column floaters currently available in the open literature. Johannessen et al. (2006) and Hennig et al. (2011) investigated the dynamic air gap, wave loads and floating platform response under extreme wave conditions. Both investigations reported that a wave-in-deck event can lead to an additional extreme response mechanism and a step change in the extreme loading magnitude in tendons. It must be noted that complete 
and detailed results of these types of experiments are usually subjected to project confidentiality requirements and are therefore not available in the public domain.

Model tests are arguably the best approach for estimating wave-in-deck loads (Scharnke et al., 2014). However, model testing is costly, timeconsuming and involves a number of drawbacks such as scaling effects. It is therefore not surprising that the use of computational fluid dynamics (CFD) based methods for calculating wave induced loads on offshore structures has received increasing amount of attention in later years. Commonly used commercial codes such as STAR-CCM+ and ANSYS FLUENT are available for modelling and solving wave-indeck impact problems using the volume of fluid (VOF) method to capture free-surface hydrodynamic flows (CD-Adapco, 2012, Fluent, 2009). There is a large body of work on CFD investigations of wave impact loads on fixed deck structures (Birknes-Berg and Johannessen, 2015, Iwanowski et al., 2014, Ren and Wang, 2004). However, very little work on fixed with columns and floating structures has been reported to date (Iwanowski et al., 2009, Lee et al., 2014).

The scope of the present investigation is to predict the global and local wave loads of a fixed multicolumn offshore platform (rigidly mounted TLP) at a model scale of 1:125 due to extreme wave events corresponding to a 10,000-year cyclonic condition $\left(H_{s}=22.125 \mathrm{~m}, T_{p}=\right.$ $17.0 \mathrm{~s}$ at full scale). Regular wave tests with $H=1.13-1.36 H_{s}$ were conducted in the Australian Maritime College (AMC) towing tank. Using data from repeated runs, uncertainty tests of wave elevations, global wave impact forces and slamming pressures at the deck underside were performed. In addition, the commercial CFD code STAR-CCM+ was used to investigate the characteristics of unidirectional regular wave impact on the model. The numerical results were then validated against the measurements acquired in model tests.

\section{EXPERIMENTAL SETUP}

The TLP model used in this investigation was tested as a rigid body (Fixed multicolumn TLP). The model had two main modules namely a hull module (columns and pontoons) and a topside deck module. The hull module was represented by four circular columns and four square pontoons with their scaled dimensions derived from the SNORRE-A TLP. The model was fixed by attaching it to a rigid beam mounted across the AMC towing tank. All details of model's dimensions and instrumentation, as well as the experimental setup, can be found in the open literature (Abdussamie et al., 2016a, Abdussamie et al., 2016b).

The model had a static deck clearance (freeboard), $a_{0}$, of $120 \mathrm{~mm}$ at the operating draft. The effect of deck clearance reduction on the magnitude of global and local wave impact loads was investigated by reducing the original $a_{0}$ by $10 \mathrm{~mm}$. A total of seven conditions were examined experimentally and numerically with the TLP model being fixed-in-place (Table 1).

Table 1: Test conditions at wave period $T=1.52 \mathrm{~s}$ (17.0 $\mathrm{s}$ full scale).

\begin{tabular}{lllll}
\hline \hline \multirow{2}{*}{$\begin{array}{l}\text { Test } \\
\text { condition }\end{array}$} & \multicolumn{2}{l}{ Full scale } & \multicolumn{2}{c}{ Model scale $(1: 125)$} \\
\cline { 2 - 5 } & $a_{0}(\mathrm{~m})$ & $H(\mathrm{~m})$ & $a_{0}(\mathrm{~mm})$ & $H(\mathrm{~mm})$ \\
\hline 1 & 15.00 & 25.00 & 120 & 200 \\
2 & 15.00 & 27.50 & 120 & 220 \\
3 & 15.00 & 28.88 & 120 & 231 \\
4 & 15.00 & 30.00 & 120 & 240 \\
5 & 13.75 & 25.00 & 110 & 200 \\
6 & 13.75 & 27.50 & 110 & 220 \\
7 & 13.75 & 30.00 & 110 & 240 \\
\hline \hline
\end{tabular}

The natural frequency of the testing assembly in the $x$ - and $z$-directions was obtained from free decay tests in water as $7.33 \mathrm{~Hz}$ and $15.00 \mathrm{~Hz}$, respectively.

\section{EXPERIMENTAL DATA ANALYSIS}

Condition $2(H=220 \mathrm{~mm}, T=1.52 \mathrm{~s}$ and $\mathrm{a} 0=120 \mathrm{~mm})$ is presented to illustrate the good repeatability of the towing tank test. Fig. 1 shows the surface wave elevations measured at approximately $700 \mathrm{~mm}$ in front of the deck leading edge, in four repeated runs. Good qualitative repeatability can be seen among the four runs for both wave probes. A coefficient of variation $(\mathrm{CV}=\sigma /$ mean $)$ in crest height of approximately $3.6 \%$. Lower values of $\mathrm{CV}(\approx 2.0 \%)$ were obtained during wave calibration process; without the model being in the tank.

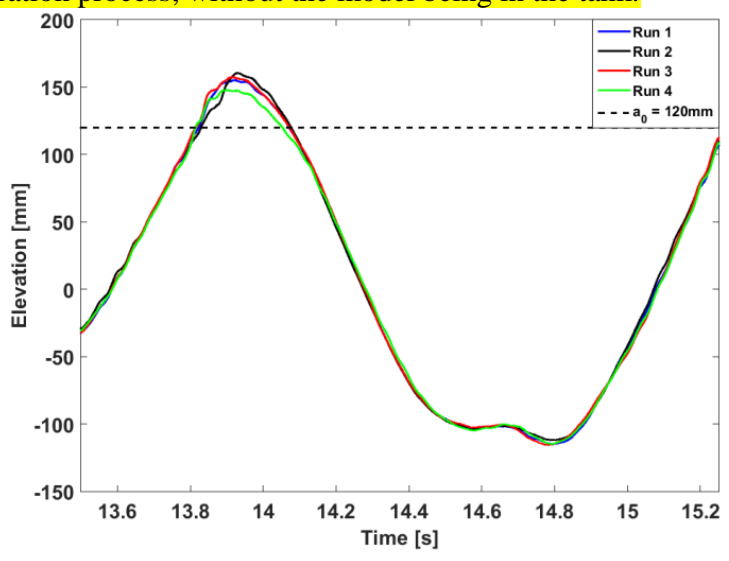

Fig. 1: Time history of wave surface elevation at the front of the model measured in four repeated runs for condition 2.

The global forces in the $x$ - and $z$-direction, denoted by $F_{x}$ and $F_{z}$, are shown in Figs. 2 and 3, respectively. Force peaks of the horizontal force, $F_{\mathrm{x}}$, were obtained for both directions as defined by $F_{x}(+)$ and $F_{x}(-$ ), whilst the upward and downward components of $F_{z}$ are denoted as $F_{z}(+)$ and $F_{z}(-)$. By analysing the time history of $F_{\mathrm{x}}$ and $F_{\mathrm{z}}$ using Fast Fourier Transform (FFT), the dynamic response of the model was found to contaminate the load cell signal response in the $z$-direction, whereas a minimal effect of such was observed in the $x$-direction. Table 2 summarises the peaks of force components where a large CV was obtained for $F_{z}$, particularly in the downward direction which can be attributed to the contribution of the structural dynamic response.
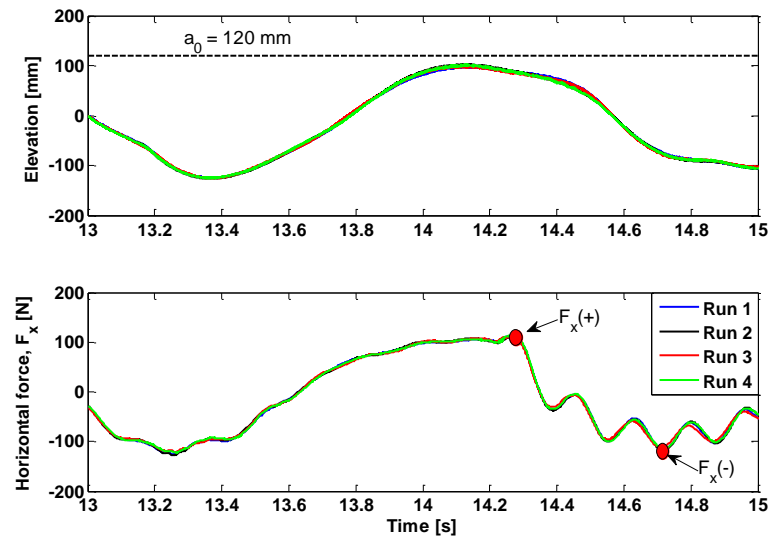

Fig. 2: Simultaneous measurements in four repeated runs for condition 2: wave elevation at 100 from the deck LE; wave impact horizontal force, $F_{x}$ (bottom). 

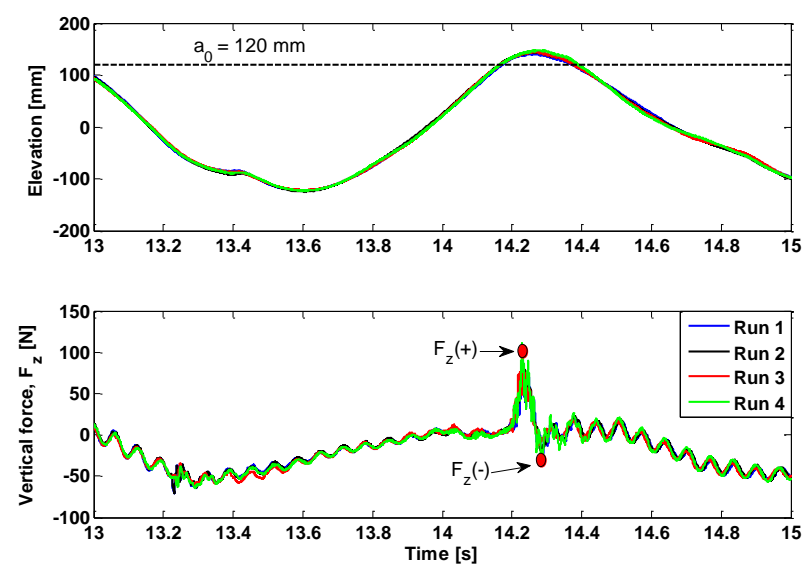

Fig. 3: Simultaneous measurements in four repeated runs for condition 2: wave elevation at the deck mid-span (top); wave impact vertical force, $F_{\mathrm{z}}$ (bottom).

Table 2: Force maxima (+) and minima (-) of $F_{x}$ and $F_{z}$ extracted from four repeated runs for condition 2.

\begin{tabular}{lllll}
\hline \hline \multirow{2}{*}{ Run id } & \multicolumn{4}{c}{ Force $[\mathrm{N}]$} \\
\cline { 2 - 5 } & $F_{x}(+)$ & $F_{x}(-)$ & $F_{z}(+)$ & $F_{z}(-)$ \\
\hline 1 & 113.1 & -117.1 & 85.4 & -24.8 \\
2 & 111.8 & -117.3 & 77.9 & -17.92 \\
3 & 110.8 & -111.8 & 80.8 & -11.4 \\
4 & 113.0 & -115.4 & 109.8 & -22.6 \\
Mean & 112.2 & -115.4 & 88.5 & -19.2 \\
$\sigma$ & 1.1 & 2.5 & 14.5 & 5.9 \\
$\mathrm{CV}$ & $1 \%$ & $2 \%$ & $16 \%$ & $31 \%$ \\
\hline \hline
\end{tabular}

The time history of the corresponding wave-in-deck impact pressures measured around the aft columns at pressure transducers PT\#15 and PT\#16 are presented in Fig. 4. Overall, a large variation in pressure measurements amongst repeated runs having almost identical wave condition can be appreciated. The values of slamming pressure, $P_{i}$, extracted from the associated runs are summarised in Table 3 which demonstrated high variability.
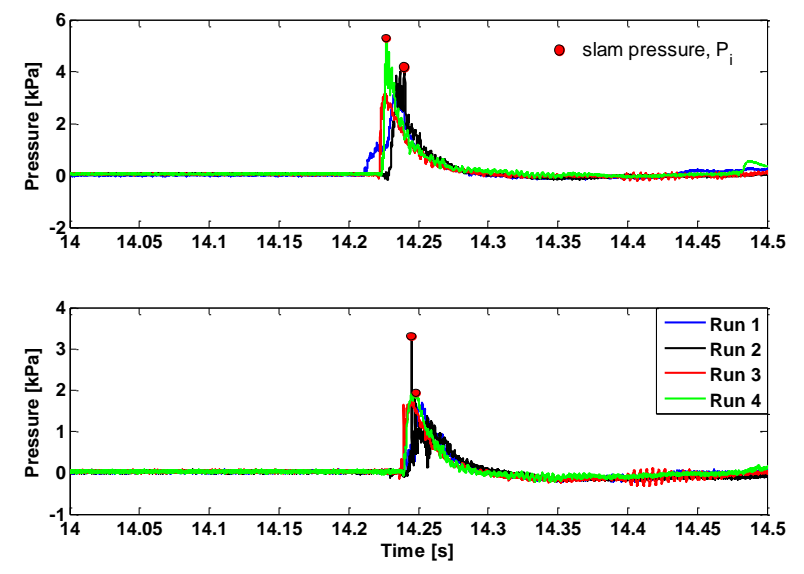

Fig. 4: Wave-in-deck pressures around the aft column measured in four repeated runs for condition 2: PT\#15 (top); PT\#16 (bottom).
Table 3: Slamming pressures, $P_{\mathrm{i}},(\mathrm{kPa})$ measured in four repeated runs around the aft column for condition 2.

\begin{tabular}{llllllll}
\hline \hline PT\# & Run 1 & Run 2 & Run 3 & Run 4 & Mean & $\sigma$ & CV \\
\hline 15 & 3.1 & 4.3 & 3.1 & 5.2 & 3.9 & 1.0 & $26 \%$ \\
16 & 1.7 & 3.2 & 1.9 & 1.8 & 2.2 & 0.7 & $33 \%$ \\
\hline \hline
\end{tabular}

\section{CFD MODELLING}

A commercial CFD code STAR-CCM+ (Release 10) developed by $\mathrm{CD}$-adapco was used for simulating the physics of the wave-in-deck problem. In this work, since the CFD results were validated against model test results at a small scale, laminar flow was assumed for all numerical simulations. Based on isothermal and laminar flow assumptions, a system of partial differential equations governing the conservation of mass and momentum of a fluid was solved numerically using the finite volume method (Versteeg and Malalasekera, 2007). The VOF model implemented in the code was used for capturing the interface between two immiscible fluids, hereafter water and air phases. This implies that the trapped air involved in the wave-in-deck problem was accounted for. Both phases were modelled as an incompressible fluid unless otherwise mentioned. The physical properties (e.g., density) of water and air were expressed as a volume fraction of each fluid during solving the process. Further theoretical details of the numerical method can be found in the STAR-CCM+ user guide (CDAdapco, 2012). For the present numerical study, two different computational domains were created namely: a wave generation domain and a wave-structure interaction domain for the fixed TLP model. In the later, an overset mesh was used to allow for modelling the rigid body motions. The CFD analyses were conducted as per the following procedure:

1- Wave generation (similar to the wave calibration conducted in model tests) - a numerical wave tank (NWT) or wave generation domain was created without the TLP model being present in order to investigate wave quality generated against the theoretical wave elevations.

2- Wave-structure interaction (similar to the wave impact tests conducted in towing tank) - the TLP model was setup in the domain and subjected to unidirectional regular waves tested in step 1 .

A 3D trimmed mesh with 1 cell layer into the $y$-direction was generated to investigate the numerical quality of the generated waves. A numerical domain was bounded by $x \in[0,22], y \in[0,0.1]$ and $z \in[0$, 2] $\mathrm{m}$. The length of the domain $(22 \mathrm{~m})$ was approximately $6 \lambda$ where $\lambda$ is the wavelength $(\lambda=3.61 \mathrm{~m})$. The mesh domain was divided into several parts in the vertical $z$-direction including "water", "free surface" and "air" zones. The authors have previously identified that approximately 20 - 30 cells per wave height and 80 cells per wavelength are essential for the accurate prediction of wave propagation in the free surface part (Abdussamie et al., 2014a). Moreover, a time step of $0.001 \mathrm{~s}$ was found to be adequate to capture the dynamics of a sharp wave free surface and to maintain optimal solution using the High-Resolution Interface Capturing (HRIC) scheme (Abdussamie et al., 2014a). It should be noted that the used CFD solver automatically changes the scheme used for transport volume fraction based upon the upper and lower limits of the Courant number. Pure HRIC scheme is used when the local Courant number is below the lower limit (0.5), whereas a pure first-order upwind scheme is automatically activated for Courant number higher than the upper limit (1.0). Both schemes are blended for intermediate values (CD-Adapco, 
2012).

At the initial condition (time $=0.0$ ), the wave profile was fully developed in the zone $x=0$ to $x=2 \lambda$. This minimised the time required for incoming waves to reach $x=10.8 \mathrm{~m}$ which was selected to be the location of the model's centroid during the simulations of wavestructure interaction. Wave damping was applied over the last $2 \lambda$ "damping zone" before the downstream boundary $(x=22.0 \mathrm{~m})$. The method proposed by Choi and Yoon (2009) is implemented into the code for damping the vertical motion of the free surface.

In order to minimise reflected waves from the far-field boundaries, which can corrupt the numerical solution, the model's centroid was set at $x=10.8 \mathrm{~m}(\approx 3 \lambda$ upstream and $3 \lambda$ downstream). Same mesh and time settings used during wave generation was employed during wave impact tests except (i) domain size in $y$-direction increased from $0.1 \mathrm{~m}$ to $1.775 \mathrm{~m}$ (half of the width of AMC towing tank). (ii) mesh refinement was created around the model in order to capture fine flow details such that a surface mesh of $3.125 \mathrm{~mm}$ was applied on the entire body surfaces.

In order to accurately predict wave impact forces and pressures acting on the deck underside of the model, a uniform surface mesh with different levels of refinement was examined throughout the deck underside area $(608 \mathrm{~mm} \times 304 \mathrm{~mm})$. Table 4 summarises three levels of mesh refinement conducted in this study.

Table 4: Mesh size levels at the deck underside tested.

\begin{tabular}{llll}
\hline \hline Level & $\begin{array}{l}\text { Mesh size at the } \\
\text { model's surfaces } \\
(\mathrm{mm})\end{array}$ & $\begin{array}{l}\text { Mesh size at the } \\
\text { deck underside } \\
(\mathrm{mm})\end{array}$ & $\begin{array}{l}\text { Total no. of } \\
\text { cells }\end{array}$ \\
\hline 1 & 3.125 & 3.125 & $2.33 \times 10^{6}$ \\
2 & 3.125 & 1.5625 & $2.69 \times 10^{6}$ \\
3 & 3.125 & 0.78125 & $4.10 \times 10^{6}$ \\
\hline \hline
\end{tabular}

Air density and its pressure derivative were defined by means of userdefined field functions derived from the following equations:

$$
\begin{aligned}
& \rho_{\text {air }}=\rho_{\text {air }}^{\prime}+\frac{p}{C_{\text {air }}^{2}} \\
& \frac{d \rho_{\text {air }}}{d p}=\frac{1}{C_{\text {air }}^{2}}
\end{aligned}
$$

where $\rho_{\text {air }}^{\prime}=1.18415 \mathrm{~kg} / \mathrm{m}^{3}$ is the incompressible air density, $C=331$ $\mathrm{m} / \mathrm{s}$ is the sound speed in air, and $p$ is pressure.

In order to model the desired wave characteristics, an incoming wave with appropriate height and wave period was specified at the inflow domain boundary $(x=0.0)$. At this boundary of the domain, a velocity inlet condition was specified, where the velocity field and volume fraction of water and air were defined using the Stokes fifth order wave theory (Fenton, 1985). Hydrostatic pressure boundary condition was assigned at the top of the tank $(z=2.0 \mathrm{~m})$ and its end at $x=22.0 \mathrm{~m}$. Noslip boundary condition was used on the tank bottom $(z=0)$, tank side $(y=1.775 \mathrm{~m})$ and the TLP model boundary surfaces. Whilst the other side of the domain $(y=0)$ was set with a symmetry boundary condition. In the simulations of floating conditions, the model was released 50 time steps after starting the solution (CD-Adapco, 2012).

The second-order discretisation of unsteady terms in momentum equations and HRIC scheme for the solution of the volume fraction equations was adopted in all simulations. The pressure-velocity coupling was performed by the SIMPLE (Semi-Implicit Method for
Pressure-Linked Equations) algorithm. Second order discretisation for convective terms of VOF model. These settings were selected as a reasonable compromise between accuracy and computational time.

Wave surface elevations were obtained at a volume fraction of the water of 0.5 along the computational domain with and without the model in place. As an example, Fig. 5 shows the wave elevation for condition 1 compared with the theoretical one. The theoretical wave was approximated by Stokes fifth order without the TLP model being in place. The effect of the model's presence on the approaching waves can be seen at times 3T and 6T where a slight phase shift started to form between the predicted and theoretical wave elevations far away from the inlet boundary condition. The damping zone, starting from $x=$ $14.8 \mathrm{~m}$, was also affected by the simulation time. It should be noted that it is difficult to simulate waves with zero transport losses numerically due to relaxed spatial and temporal discretisation (Saripilli et al., 2014).
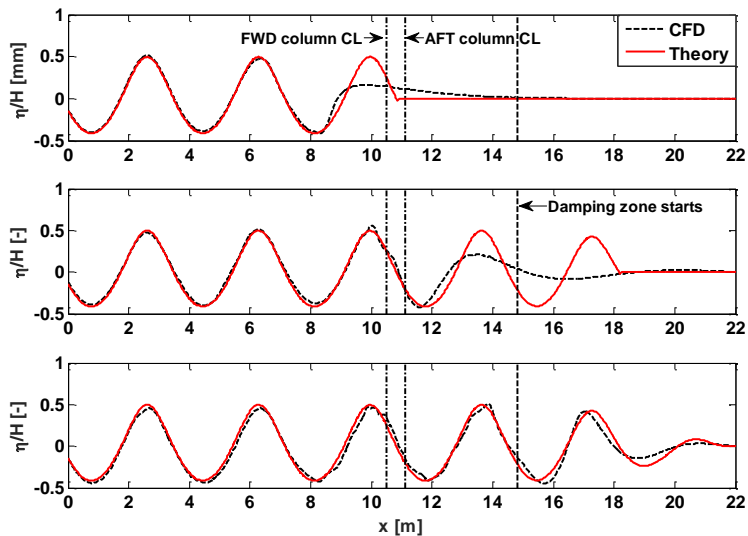

Fig. 5: Comparisons between the CFD (dashed line) and theoretical (solid line) surface elevation of propagating waves along the computational domain for condition 1 at: $t=T$ (top); $t=3 T$ (middle); $t$ $=6 T$ (bottom).

The effect of mesh refinement on the magnitude of wave impact loads was also tested. Fig. 6 shows the time history of $F_{x}$ and $F_{z}$ acting on the fixed model for condition $2\left(H=220 \mathrm{~mm}, T=1.52 \mathrm{~s}, a_{0}=120 \mathrm{~mm}\right)$. CFD does not show oscillations in the force time histories, confirming the oscillations in the model test are due to the structural response.
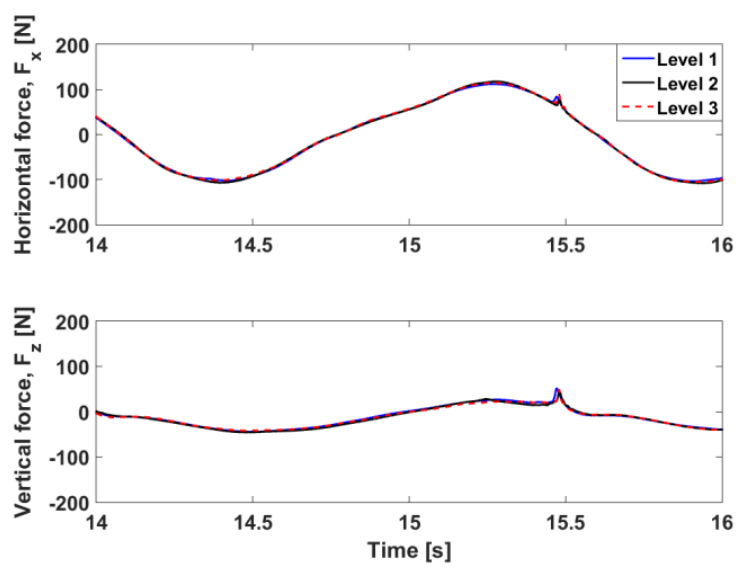

Fig. 6: Time history of the global wave impact forces predicted by CFD using different levels for mesh size for condition 2: horizontal force, $F_{x}$ (top); vertical force, $F_{z}$. 


\section{RESULTS AND DISCUSSION}

Raw experimental data and CFD results are discussed and compared below. In all CFD simulations, the reference mesh (level 1) was used when evaluating the global wave impact loads. Local wave impact loads at the deck underside were captured using the mesh refinement at level 2.

Fig. 7 shows the CFD wave elevation and the measured one $(\mathrm{H}=231$ $\mathrm{m}, \mathrm{T}=1.52 \mathrm{~s})$. The theoretical wave elevation based on Stokes 5 th order is also given. It is shown that CFD predicts well both the amplitude and the frequency of the incoming waves.

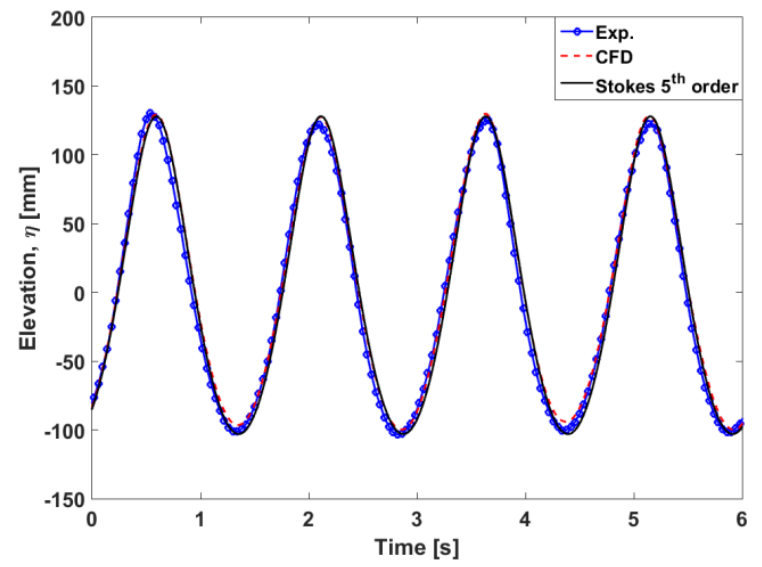

Fig. 7: Wave calibration of incident wave elevation $(\mathrm{H}=231 \mathrm{~m}, \mathrm{~T}=$ $1.52 \mathrm{~s})$.

The time history of global wave impact forces acting on the fixed TLP model associated with test condition 1 obtained by CFD and experiments is presented in Fig. 8. Good agreement between the CFD predictions and measured $F_{x}$ in all conditions with a mean relative error of $4 \%$ for the $F_{x}(+)$ and $4 \%$ for the $F_{x}(-)$.
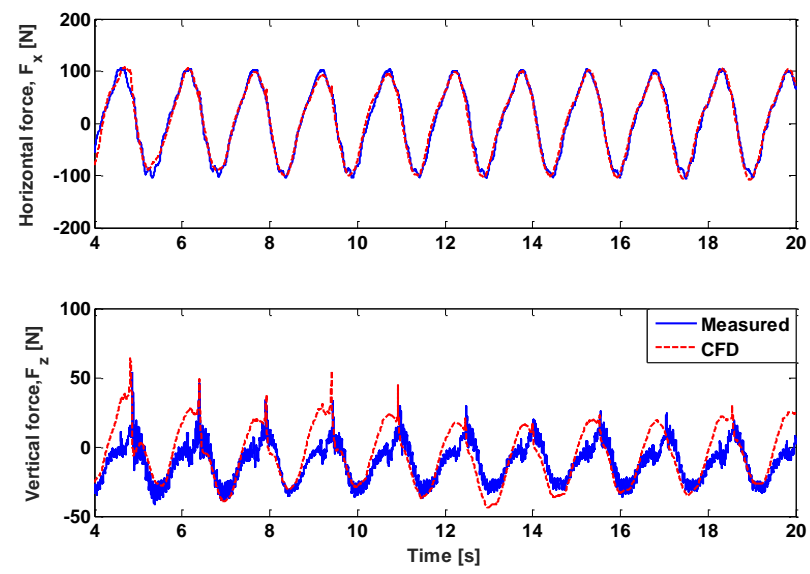

Fig. 8: Time history of global wave impact forces obtained by CFD (dashed line) and experiments (solid line) for condition 1.

The effect of air gap reduction on the global forces was examined numerically and experimentally by reducing the original deck clearance; ao by $10 \mathrm{~mm}$ ( $1.25 \mathrm{~m}$ full-scale). It was found that the reduction of deck clearance has no a large effect on the force magnitudes in both $x$ - and $z$-directions. Fig. 9 shows an example of this finding for conditions 2 and $6(\mathrm{H}=220 \mathrm{~mm}, \mathrm{~T}=1.52 \mathrm{~s})$.

CFD models enabled the wave impact force component acting on the topside deck (wave-in-deck force) to be isolated from the total hydrodynamic wave force acting on the TLP model. In most cases, the magnitude of the horizontal wave-in-deck forces $\left(\mathrm{F}_{\mathrm{xd}}\right)$ was found to be much smaller than the vertical wave-in-deck forces $\left(\mathrm{F}_{z \mathrm{~d}}\right)$. However, the effect of deck clearance reduction on the force magnitudes was found to be more pronounced in $\mathrm{F}_{\mathrm{xd}}$ than in $\mathrm{F}_{\mathrm{zd}}$. For instance, at time $=11.0 \mathrm{~s}$ (Figs. 10 and 11) an additional water reflection and the column overtopping at lower deck clearance $\left(\mathrm{a}_{0}=110 \mathrm{~mm}\right)$, which might decrease the amount of wave energy reaching into the underdeck region, can be seen.
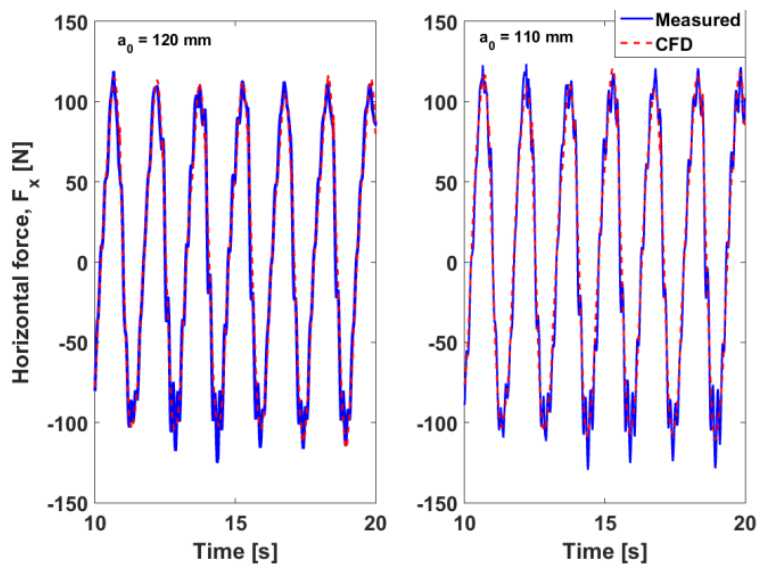

Fig. 9: The effect of deck clearance $\mathrm{a}_{0}$ on the horizontal force acting on the TLP model: condition 2 (left) and condition 6 (right).
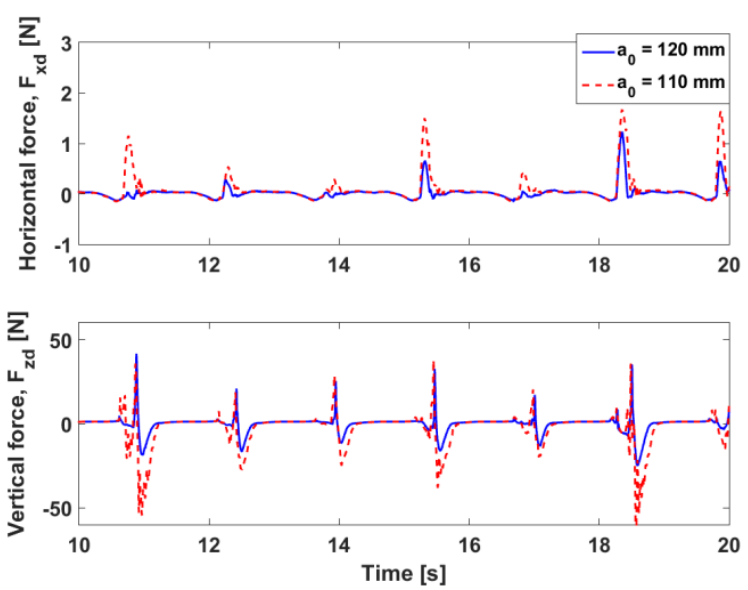

Fig. 10: The effect of deck clearance on wave forces acting on topside deck: condition 2 (top) and condition 6 (bottom).

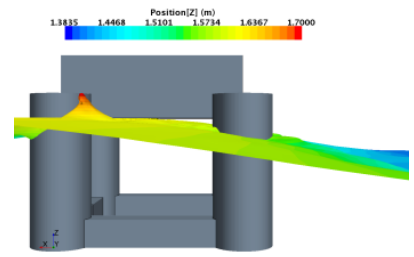

$\mathrm{a}_{0}=120 \mathrm{~mm}$

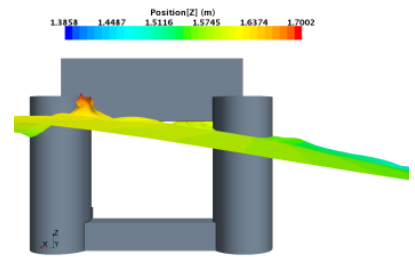

$\mathrm{a}_{0}=110 \mathrm{~mm}$
Fig. 11: Snapshots showing the interaction between a large wave and the TLP model at $t=11.0 \mathrm{~s}$ : condition 2 (left) and condition 6 (right). 
Fig. 12 demonstrates the effect of mesh resolution on the magnitude of slamming pressure at PT\#16. CFD simulations with Mesh Level $1(\approx$ 1.3 cells per transducer diameter) predicted approximately $88 \%$ of the measured slamming pressure (1793 Pa), whilst the predicted slamming pressure increased to $95 \%$ using Mesh Level $2 \approx 2.6$ cells per transducer diameter). This implies that fine surface mesh was necessary to capture such slamming pressure at a discrete point. Mesh Level 2 was, therefore, selected for further analysis.

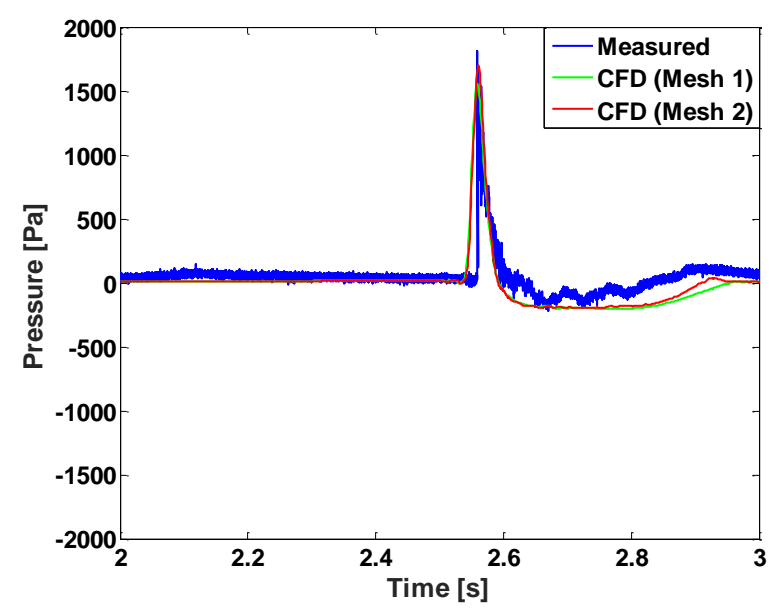

Fig. 12: Time history of wave-in-deck pressure on fixed multicolumn platform model at PT\#16 (condition 3). CFD models used incompressible air.

In order to quantify the air content associated with the wave impact, the maximum pressure and the volume fraction of the water phase over the deck area were obtained at each time step using CFD models. This technique proved to be more effective and less sensitive to mesh resolution than the prediction of slamming pressure at a discrete point. Fig. 13 shows a single wave impact in the deck area for the deck only (without columns/pontoons) and for the fixed multicolumn model computed with incompressible air. Each wave impact caused at least two consecutive slamming events at the deck underside i.e. a step change in the pressure magnitude (denoted by letters $a-d$ ). Table 5 summarises the predicted peak pressures and the associated percentage of water content for all wave slamming events a-d depicted in Fig. 13.
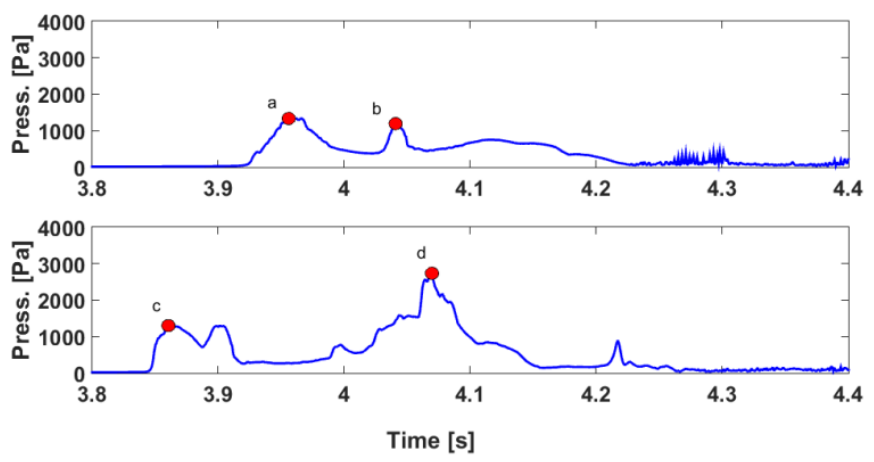

Fig. 13: Time history of maximum pressure at the deck underside. From top to bottom: fixed deck and fixed TLP.

Pairwise comparisons between the peak pressure and the water contents (volume fraction) can be made in Figs. 14 and 15 (only half of the models are shown due to symmetry).
Table 5. Maximum pressure over the deck area and the associated water content. Fig. 13 shows the wave slamming events $\mathrm{a}-\mathrm{d}$.

\begin{tabular}{|c|c|c|c|}
\hline Model & Slamming & Peak pressure $(\mathrm{Pa})$ & Water content $(\%)$ \\
\hline \multirow{2}{*}{$\begin{array}{l}\text { Fixed } \\
\text { deck }\end{array}$} & $\mathrm{a}$ & 1334 & 50 \\
\hline & $\mathrm{b}$ & 1140 & 65 \\
\hline \multirow{2}{*}{$\begin{array}{l}\text { Fixed } \\
\text { TLP }\end{array}$} & $\mathrm{c}$ & 1337 & 80 \\
\hline & d & 2770 & 30 \\
\hline
\end{tabular}
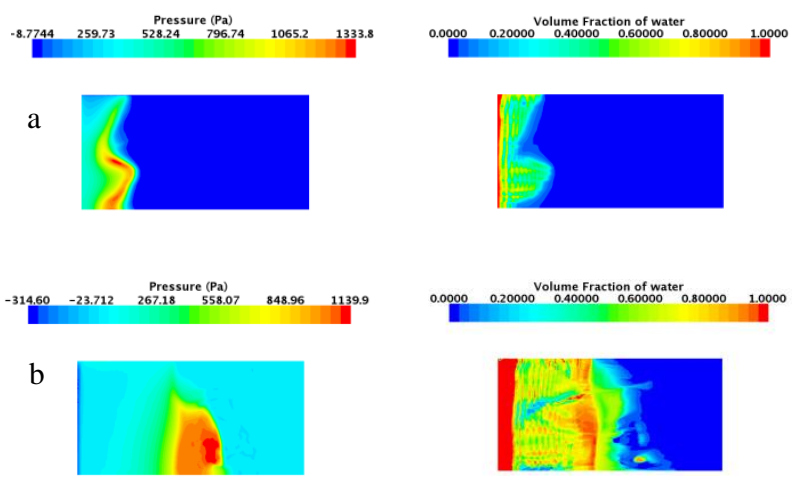

Fig. 14: Snapshots of wave slamming pressures and water content at the underside of a fixed deck.
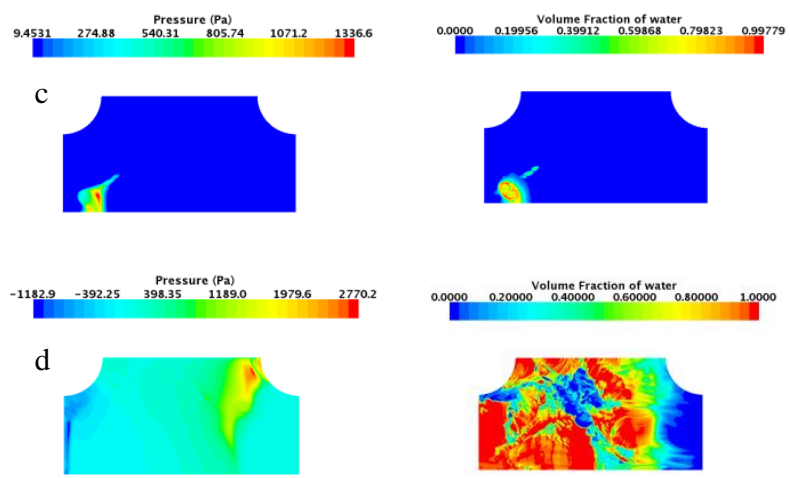

Fig. 15: Snapshots of wave slamming pressures and water content at the deck underside of the fixed TLP.

It should be noted that the two consecutive pressure peaks occur in the forward and the aft section of the deck underside, respectively. On both occasions, the part of the deck experiencing the pressure peak was exposed to a mixture of water and air phases. For instance, a volume fraction of the water phase of approximately 0.5 (50\% air) was found with the wave slamming on the fixed deck (Fig. 14a). By investigating the volume fraction of the air underneath the deck structure, it was found that not only the air phase filled the interface cells but an actual air cavity was also formed during the deck impact. This occurred in all simulated cases such that the deck area exposed to a wave slamming event was found to be in contact with a water-air mixture with a significant proportion of air phase. This highlights the necessity for numerical two-phase simulations to accurately model the wave-in-deck problems. Another observation is that the presence of the hull (columns + pontoons) had a large effect on the pressure magnitude, as the second pressure peak significantly increased (almost doubled). 
The effect of air compressibility on the magnitude and time history of wave-in-deck impact pressure at a discrete point (PT\#16) can be seen in Fig. 16. When the air was modelled as a compressible phase, the peak pressure reduced from $1700 \mathrm{~Pa}$ to $1334 \mathrm{~Pa}(\approx 21.7 \%$ reduction $)$.

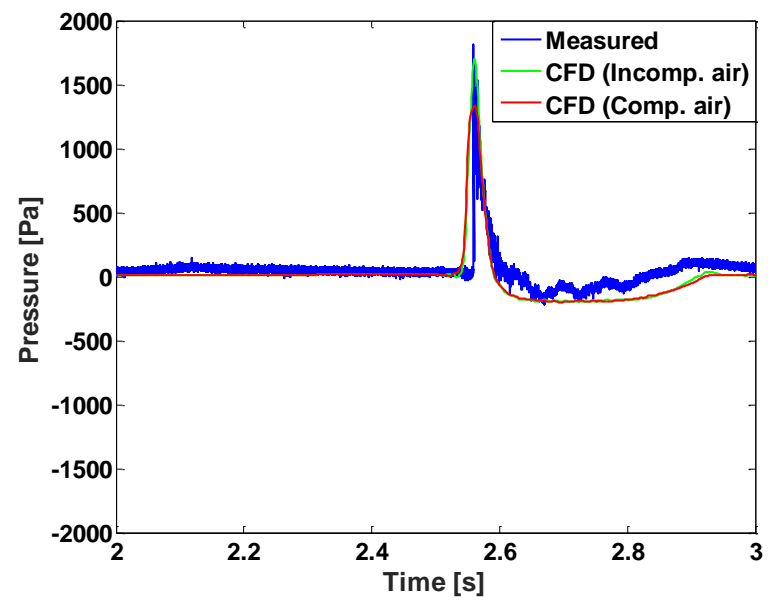

Fig. 16: Time history of wave-in-deck pressure on the fixed multicolumn platform model at PT\#16 (condition 3).

\section{CONCLUSIONS}

On the basis of the findings reported in this investigation, the following conclusions can be drawn:

- Experimental data analyses showed large variability in the magnitude and duration of wave-in-deck slamming pressures associated with extreme wave conditions. It is therefore recommended to conduct multiple repeated runs (more than $5)$ per each test condition in order to minimise the variation in the mean value of slamming pressure to be used for validation CFD models.

- Good agreement was achieved between the predicted and measured global horizontal force $\left(F_{x}\right)$ due to extreme wave impact with a mean relative error of $4 \%$.

- $\quad$ For the global vertical force $\left(F_{\mathrm{z}}\right)$, the predicted force peaks in the $F_{z}(+)$ was found to fairly agree with the measured one. Such discrepancy was caused by the large structural dynamic response of the model in the $z$-direction observed in model tests.

- Impact pressures were obtained at a discrete point and over the whole exposed area of the deck. Because the slamming pressure is an extremely localised phenomenon, predicting wave impact pressure at a discrete point, both in model tests and CFD-based codes, remains challenging.

- Obtaining the wave-in-deck slamming pressures over an exposed area using CFD simulations was more effective and provided insights into the pressure changes due to air compressibility and its content. In all simulated cases, the deck area exposed to a wave slamming event was found to be in contact with a water-air mixture with a significant proportion of air phase.

\section{REFERENCES}

Abdussamie, N., Ojeda, R., Amin, W., Thomas, G. and Drobyshevski, Y. "Prediction of Wave-in-Deck Loads on Offshore Structures Using CFD". the 19th Australasian Fluid Mechanics Conference, 2014a Melbourne, Australia. AFMS.

Abdussamie, N., Ojeda, R., Drobyshevski, Y., Thomas, G. and Amin, W. 2016a. "Experimental Investigation of Extreme Wave Impacts on a Rigid TLP Model in Cyclonic Conditions". Ships and Offshore Structures.

Abdussamie, N., Ojeda, R., Drobyshevski, Y., Thomas, G. and Amin, W. 2016b. "Measurements of Global and Local Effects of Wave Impact on a Fixed Platform Deck". the Proceedings of the Institution of Mechanical Engineers, Part M: Journal of Engineers for the Maritime Environment.

Abdussamie, N., Thomas, G., Amin, W. and Ojeda, R. "Wave-in-Deck Forces on Fixed Horizontal Decks of Offshore Platforms". Proceedings of the ASME 33rd International Conference on Ocean, Offshore and Arctic Engineering, OMAE, 2014b San Francisco, CA, USA. American Society of Mechanical Engineers.

API 2007. "Recommended Practice for Planning, Designing and Constructing Fixed Offshore Platforms-Working Stress Design, 2A-WSD". American Petroleum Institute.

API 2010. "Planning, Designing, and Constructing Tension Leg Platforms: API Recommended Practice 2T" Third Edition. USA: American Petroleum Institute, API.

Baarholm, R. "Experimental and Theoretical Study of ThreeDimensional Effects on Vertical Wave-in-Deck Forces". Proceedings of the ASME 28th International Conference on Ocean, Offshore and Arctic Engineering, OMAE, 2009 Honolulu, Hawaii, USA. American Society of Mechanical Engineers.

Bhat, S. S. 1994. "Wave Slamming on a Horizontal Plate". MSc thesis, University of British Columbia.

Birknes-Berg, J. and Johannessen, T. "Methods for Establishing Governing Deck Impact Loads in Irregular Waves". The ASME 2015 34th Int. Conf. on Ocean, Offshore and Arctic Eng., OMAE2015, 2015 St. John's, Newfoundland, Canada. ASME.

CD-Adapco 2012. "User Guide - Star-CCM+ Version 7.04". CDAdapco.

Choi, J. \& Yoon, S. B. 2009. "Numerical Simulations Using Momentum Source Wave-Maker Applied to RANS Equation Model". Coastal Engineering, 56, 1043-1060.

DNV 2010. "Recommended Practice DNV-RP-C205: Environmental Conditions and Environmental Loads". Høvik, Norway: Det Norske Veritas, DNV.

Fenton, J. D. 1985. "A Fifth-Order Stokes Theory for Steady Waves". Journal of Waterway, Port, Coastal, and Ocean Engineering, 111, 216-234.

Fluent, A. 2009. "Ansys Fluent 12.0 User Guide". ANSYS Inc.

Hennig, J., Scharnke, J., Buchner, B. and van den Berg, J. "Extreme Load-Response Mechanisms of a Tension Leg Platform Due to Larger Wave Crests: Some Results of the "Crest'JIP". ASME 2011 30th International Conference on Ocean, Offshore and Arctic Engineering, 2011. American Society of Mechanical Engineers, 855-864.

ISO 2007. "Petroleum and Natural Gas Industries-Fixed Steel Offshore Structures", International Organization for Standardization. . In: ORGANIZATION, I. S. (ed.) ISO 19902.

Iwanowski, B., Lefranc, M. and Wemmenhove, R. "CFD Simulation of Wave Run-up on a Semi-Submersible and Comparison with Experiment". Proceedings of the ASME 28th International 
Conference on Ocean, Offshore and Arctic Engineering, OMAE, 2009. ASME.

Iwanowski, B., Vestbostad, T. and Lefranc, M. "Wave-in-Deck Load on a Jacket Platform, CFD Calculations Compared with Experiments". The ASME 33rd Int. Conf. on Ocean, Offshore and Arctic Eng., OMAE, 2014 San Francisco, CA, USA. ASME.

Johannessen, T., Haver, S., Bunnik, T. and Buchner, B. 2006. "Extreme Wave Effects on Deep Water TLPs Lessons Learned from the Snorre A Model Tests". Proc. Deep Offshore Technology 2006, 28-30.

Kaplan, P., Murray, J. and Yu, W. 1995. "Theoretical Analysis of Wave Impact Forces on Platform Deck Structures". Offshore Technology Conference Houston, TX.

Lee, S.-K., Yu, K. \& Huang, S. C. "CFD Study of Air-Gap and Wave Impact Load on Semisubmersible under Hurricane Conditions". Proceedings of the ASME 33th International Conference on Ocean, Offshore and Arctic Engineering, OMAE, 2014 San Francisco, CA, USA. ASME.

Ren, B. \& Wang, Y. 2004. "Numerical Simulation of Random Wave Slamming on Structures in the Splash Zone". Ocean engineering, 31, 547-560.
Saripilli, J. R., Joga, R. K., Dhavalikar, S. and Kar, A. R. "Simulation of Numerical Wave Tanks for Generating Irregular Waves and Forward Speed Effects". The Twenty-fourth International Ocean and Polar Engineering Conference, 2014. International Society of Offshore and Polar Engineers.

Scharnke, J. and Hennig, J. "Vertical Wave Impact Loading on a Fixed Platform Deck". Proceedings of the ASME 2015 34th International Conference on Ocean, Offshore and Arctic Engineering, OMAE2015, 2015 St. John's, Newfoundland, Canada. American Society of Mechanical Engineers.

Scharnke, J., Vestbostad, T., Wilde, J. d. and Haver, S. K. "Wave-inDeck Impact Load Measurements on a Fixed Platform Deck". Proceedings of the ASME 33rd International Conference on Ocean, Offshore and Arctic Engineering, OMAE, 2014 San Francisco, CA, USA. American Society of Mechanical Engineers.

Versteeg, H. K. and Malalasekera, W. 2007. "An Introduction to Computational Fluid Dynamics: The Finite Volume Method", Prentice Hall. 